\title{
The host preferences of Nuttalliella namaqua (Ixodoidea: Nuttalliellidae): A generalist approach to surviving multiple host-switches
}

Ben J. Mans • Daniel G. de Klerk • Ronel Pienaar • Abdalla A. Latif

\begin{abstract}
Nuttalliella namaqua has been described as a "living fossil" and the closest extant species to the ancestral tick lineage. It was previously proposed that the Nuttalliella lineage parasitized reptile-like mammals in the Permian and had to switch hosts several times due to mass or host lineage extinctions. Extant hosts include girdled lizards and murid rodents. The current study extends knowledge on the extant host range of $N$. namaqua using gut-meal analysis of field collected specimens. Nymphs and females can parasitize a variety of reptiles that includes skinks, geckos and girdled lizards. Blood-meal from a hyrax was also detected in a specimen suggesting that $N$. namaqua could parasitize a broader range of mammals than the previously suggested murid rodents. Rather than being host specific, N. namaqua is proposed to be a generalist and the ability to switch and parasitize multiple hosts allowed it to survive multiple mass and host lineage extinctions.
\end{abstract}

Keywords Ixodida, Nuttalliella namaqua, • host $\bullet$ lizards $\bullet$ mammals $\bullet$ blood-meal $\bullet$ generalist

Ben J. Mans* • Daniel de Klerk • Ronel Pienaar • Abdalla A. Latif

Parasites, Vectors and Vector-borne Diseases, Agricultural Research Council, Onderstepoort Veterinary Institute, Onderstepoort 0110, South Africa

Ben J. Mans • Abdalla A. Latif

Department of Veterinary Tropical Diseases, Faculty of Veterinary Science, University of Pretoria, Onderstepoort, South Africa

Ben J. Mans

Department of Life and Consumer Sciences, University of South Africa, South Africa

*Corresponding author: e-mail: mansb@arc.agric.za 


\section{Introduction}

Host specificity allows parasites to occupy unique niches and prevents competition for the same resources. The survival of the parasite is, however, intimately linked with that of the host and when a host becomes extinct, parasites that cannot adapt to new hosts will also succumb to a similar fate (Koh et al. 2004). A striking example of this are ticks, with at least sixty-three species being considered endangered (Mihalca et al. 2011). A generalist host strategy allows for parasites to switch hosts, parasitize different hosts in different geographic areas, extend geographic ranges independent of host restricted habitat and facilitate host finding in host deficient environments (Krasnov et al. 2008). In terms of ticks, host specificity has not been considered to be an important factor in the evolution of blood-feeding behaviour in ticks (Klompen et al. 1996).

The Ixodida (ticks) are composed of three families, Argasidae (soft ticks 200 species), Ixodidae (hard ticks $\sim 700$ species) and the monotypic Nuttalliellidae (Barker and Murrell, 2004; Guglielmone et al. 2010). Nuttalliella namaqua has been described as a missing link between the families, since it possess features unique to either hard or soft ticks (Bedford, 1931). Adults and nymphs possess a pseudo-scutum reminiscent of the scutum of ixodids, but a leathery integument similar to argasids, and like the latter feeds fast (Bedford, 1931; Mans et al. 2011). Larvae possess a true scutum and resemble ixodids, and like the latter exhibit prolonged feeding with a slow and rapid engorgement phase (Latif et al. 2012; Mans et al. 2012). Males possess a scutum that covers most of the dorsal side, reminiscent of ixodid males (Latif et al. 2012). Several features are unique to N. namaqua, notably ball and socket-joints in adults and nymphs and secretion of excess blood-meal derived water via the malpighian system (Bedford, 1931; Mans et al. 2011). Systematic analysis suggested a basal relationship to the hard and soft tick families and it has been proposed that $N$. namaqua is a "living fossil" that dates from the Late Carboniferous-Early Permian (Mans et al. 2011; Mans et al. 2012). This would imply that this species underwent numerous host switches during its evolution. It is therefore not surprising that the host status of $N$. namaqua remains enigmatic and controversial.

The majority of adult and nymphal ticks have been collected off the host in a variety of natural habitats that include under a stone, from the ground, from the nest of the striped swallow (Hirundo abyssinica unitatis), from an abandoned eagle nest, from a rock crevice and from a rock face (Bedford, 1931; Keirans et al. 1976; El Shoura et al. 1984; Mans et al. 2011). Ten females were collected from slender-tailed meerkat (Suricata suricatta hahni) and one from Brants' karoo rat (Parotomys brantsi) (Keirans et al. 1976). Based on these collection sites, it was suggested that the preferential host could be rock hyraxes (Procavia capensis), swallows, rodents and meerkat (Keirans et al. 1976). The possibility that Agama or other lizards could be candidate hosts 
was also considered (Hoogstraal, 1985). Efforts to feed females and nymphs on chickens, pigeons, rabbits, rats or mice were, however, not successful (Hoogstraal, 1985; El Shoura, 1990). Gut meal analysis from a fieldcollected $N$. namaqua female indicated the presence of nucleated red blood cells and DNA from girdled lizards (Cordylus), while nymphs and adult females were successfully fed on lizards (Mans et al. 2011). In contrast, numerous larval ticks were found on a variety of small murid rodents (Micaelamys namaquensis, Aethomys chrysophilus and Acomys spinosissimus), suggesting that these were the natural hosts of larval N. namaqua (Horak et al. 2012). Larvae could also be successfully fed on both mice and lizards and moulted to nymphs (Latif et al. 2012; Mans et al. 2012). The question was raised whether the female analysed in the previous study (Mans et al. 2011), could have incidentally fed on a lizard and that reptiles would not be natural hosts for female ticks, even if successful feeding could be completed in the laboratory. This was investigated by gut meal analysis of additional field collected nymphs and females and the results indicated that all specimens fed on different lizards, suggesting that $N$. namaqua is a generalist.

\section{Materials and Methods}

Tick collection, dissection, blood smear preparation and genomic DNA extraction

The $N$. namaqua specimens used in the current study were collected as previously described from the same localities (Mans et al. 2011). All necessary collection and transport permits were obtained from the Veterinary Authorities (Permit number: SP2011/02/02/01). In addition permission to collect ticks from Krymekaar and Voëlklip was granted by the owner, Mr. A. van Heerden.

Tick dissection and gut preparation

Tick guts were processed as previously described (Mans et al. 2011). Briefly, ticks were embedded in molten wax and their dorsal cuticle removed under $0.9 \%$ saline solution by dissection. Guts were removed in an intact form and ruptured on a microscope slide. Half were used to prepare a blood smear that was dried for Giemsa staining. The other half was used for DNA extraction using the Qiagen Blood kit according to the manufacturer's instructions.

Tick gut meal analysis for identification of host mitochondrial DNA 
The 16S rRNA gene for lizards were amplified, cloned and sequenced as previously described (Mans et al. 2011). Briefly, primers used were for the $16 \mathrm{~S}$ gene from reptiles and include the 16SF.1 and 16SR.0 primers (Whiting et al. 2003). For each tick, ten clones were sampled and consensus sequences derived that was used to search the non-redundant database using BLASTN analysis (Altschul et al. 1990). Mammalian DNA was amplified using the L14841 and H15149 primers for the cytochrome b gene (Kocher et al. 1989), and cloned, sequenced and analysed as for the $16 \mathrm{~S}$ gene.

\section{Results}

Micro-habitats of N. namaqua

In the current study, adult females as well as nymphs were collected from a variety of micro-habitats that included the underside of a rock overhang exposed to the elements, a crevice in the ground packed with rocks and dirt that will not be accessible to large animals, on the wall of a hyrax den and under a flint with a clearing space of less than $1 \mathrm{~cm}$ (Table 1).

Gut meal analysis for hosts of $N$. namaqua

To extend the previous gut meal analysis performed on a single field collected tick specimen, eight additional field collected female ticks were analysed (Table 1). Blood smear analysis of the gut contents indicated that all ticks possessed nucleated red blood cells, which indicated that they recently fed on reptile or avian hosts. Amplification, cloning and sequencing of the $16 \mathrm{~S}$ ribosomal RNA gene indicated that these ticks fed on a variety of different lizards that included girdled lizards (Cordylid family), skinks (Mabuya) and geckos (Pachydactylus). It should be noted that at least five of the lizard species did not have sequences in the database that would allow species identification, but could be assigned to lizard genera. Amplification of the mammalian cytochrome $b$ gene was negative for most of the samples, suggesting that these specimens did not feed on any mammalian hosts. However, one specimen yielded sequences corresponding to that of a hyrax (Procavia capensis) as well as a gecko. Seven of the tick specimens only possessed one species of lizard DNA. In contrast, two specimens, including the previous described female, contained the blood-meal of three to four lizard species. 


\section{Discussion}

Analysis of gut meal content to identify the hosts of blood-feeding arthropods has been used for a number of different ecto-parasites using RFLP markers (Oshaghi et al. 2006), reverse line blot (Scott et al. 2012), PCR (Ngo and Kramer, 2003, Kent and Norris, 2005), proteomics (Wickramasekara et al. 2008) and immunological methods (Clausen et al. 1998). For most of the above methods of host detection, host reference material is necessary (Laskay et al. 2012). Since the host range of $N$. namaqua is not known, amplification with universal primers for lizards and mammals, followed by cloning and sequencing were considered the most prudent approach as evident by the discovery of at least five unique lizard species that could not be identified.

In a number of tick species, multiple hosts including mammalian, could be detected (Scott et al. 2012). In the case of $N$. namaqua, the predominant hosts detected in females were single species of lizards. However, in a limited number of samples multiple species were detected, including the mitochondrial DNA of a hyrax. These ticks most probably had multiple feeding events and stored their blood-meals over prolonged periods as observed for argasids (Mans et al. 2011). Recently, it was shown that N. namaqua females could feed multiple times, that red blood cells can be stored in an intact form between molting events and that the blood-meal may be stored for more than six months without digestion (Mans et al. 2012). This supports the notion of storage and detection of blood-meal from multiple hosts.

N. namaqua has been found in Tanzania and a wide area of southern Africa that included the Karoo, Namaqualand, Kalahari and the Soutpansberg area of the Northern Limpopo province (Keirans et al. 1976; Mans et al. 2011; Horak et al. 2012). Lizard hosts identified thus far included the Karoo girdled lizard (Karusasaurus polyzonus), the western skink (Mabuya sulcata) and Bibron's gecko (Pachydactylus bibroni). In addition, a number of unidentified species closely related to Weber's gecko (Pachydactylus weberii), the Namaqua gecko (Pachydactylus namaqua) and members of the Cordylid family were detected. The girdled lizards and geckos have specific distributions in the arid North-Western region of southern Africa, while Mabuya sulcata is widely distributed across southern Africa (Broadley, 2000; Bauer and Lamb 2005; Stanley et al. 2011). It is therefore likely that $N$. namaqua parasitizes different reptile species in other geographic regions.

The habitats where most adult and nymphal $N$. namaqua were collected (under rocks, the underside of rock overhangs, under flint and on rocks within a ground crevice) are accessible to lizards and it would seem to be unlikely habitats frequented by rodents. If eggs were laid in these environments, larvae would probably parasitize lizards. Even so, reports of larvae feeding on mice were reported even though it is not clear what the 
prevalence is on mice in general (Horak et al. 2012; Mans et al. 2012). It is furthermore intriguing that a number of females were found on burrowing mammals, such as meerkat and Brant's Karoo rat (Keirans et al. 1976), given that females feed fast (Mans et al. 2011). One possible explanation would be that these females were indeed feeding on these mammals when the animals were killed. These animals and ticks were collected on a trip to Namaqualand and South-West Africa conducted on behalf of the Transvaal Museum in 1937 by Austin Roberts and Vivian FitzsSimons (FitzsSimons, 1938). The trip extended from 6 March - 4 September 1937 and sites reported for N. namaqua collections (Keirans et al. 1976), correspond with the same dates visited during the trip, i.e. Kobos, Rehoboth (19-21 July 1937) and Port Nolloth (19-21 August 1937). From five Suricata suricatta hahni collected on the trip, two were infested with N. namaqua, while one out of three Parotomys brantsi collected were infested (Roberts, 1937). It would seem unlikely that these were incidental findings, especially since one meerkat was infected with nine female ticks. This extends the potential mammalian hosts for N. namaqua to murid rodents, meerkat, Brant's Karoo rat and hyraxes.

For nine specimens sampled, using gut blood meal analysis, nine different lizard genotypes were obtained, although the same genotype was found in different specimens. No lizard host of preference could, however, be assigned. Similarly, larvae were found on three different murid rodent species with similar infestation rates (Horak et al. 2012). The data for $N$. namaqua suggest a wide geographic distribution as well as host preference. Tentatively, it may be concluded that larvae may generally feed on rodents (no data exist for captured lizards), while nymphal and adult ticks prefer reptiles with no particular host preference. More likely, however, is the possibility that this tick is a generalist, given the fact that it parasitizes at least 14 different mammalian and reptile hosts (Krasnov et al. 2010), as well as birds (Keirans et al. 1976) (Table 2). As such, host preference might be determined by the specific habitat in which the tick finds itself at any given moment. It is therefore premature to conclude that the natural hosts of immatures or adults may be exclusively mammals or reptiles (Mans et al. 2011; Horak et al. 2012). In this regard, the generalist approach seems to hold for many argasid and ixodid tick species (Cumming, 2004; Klompen et al. 1996; Wells et al. 2012; Nava and Guglielmone, 2013).

As N. namaqua is monotypic and basal to the Ixodida, it has been suggested that this tick is a "living fossil" that dates from the time of the origin of the Ixodida and that some of its earliest hosts were reptile-like mammals (Mans et al. 2011). Given the molecular clock age estimations for the Nuttalliella genus (>280 MYA) it would be clear that this genus fed on reptiles long before the origin of mammals (Mans et al. 2011; Mans et al. 
2012). It is therefore likely that the host preference of $N$. namaqua changed over temporal time so that extant mammals and lizards would be current preferred hosts. Similarly, ixodids and argasids changed hosts many times over their evolution, so that host specificity is likely to be temporal and determined by ecology as much as host availability (Klompen et al. 1996; Estrada-Pena et al. 2010). In this regard, those lineages unable to adapt to new hosts would have become extinct and a generalist approach to host specificity (as suggested for $N$. namaqua) would be the most optimal survival strategy. This correlates with considerations that host specificity was not a major driving force in tick evolution (Klompen et al. 1996).

Acknowledgements We thank Mr. A. van Heerden for permission to search his farm for ticks. Mr. Faansie Peacock (Ditsong National Museum of Natural History) is thanked for access to the Austin Roberts archives of the Barlow Expedition. This project was funded by the Joy Liebenberg Trust (21/19/JT02) allocated to BM, an incentive funding for rated researchers grant from the National Research Foundation of South Africa (NRF-Mans 76499) and a South African National Research Foundation grant allocated to AL (NRF-Spain).

\section{References}

Altschul SF, Gish W, Miller W, Myers EW, Lipman DJ (1990) “'Basic local alignment search tool.” J Mol Biol 215: $403-410$

Barker SC, Murrell A (2004) Systematics and evolution of ticks with a list of valid genus and species names. Parasitology 129: S15-S36.

Bauer AM, Lamb T (2005) Phylogenetic relationships of southern African geckos in the Pachydactylus group (Squamata: Gekkonidae). Afr J Herpetol 54: 105-129

Bedford GAH (1931) Nuttalliella namaqua, a new genus and species of tick. Parasitol 23: 230-232

Bigalke RD, Skinner JD (2002) The Zoological Survey: an historical perspective. Trans Roy Soc S Afr 57: 3541

Broadley DG (2000) A review of the genus Mabuya in southeastern Africa (Sauria: Scincidae). Afr J Herpetol 49: 87-110.

Clausen PH, Adeyemi I, Bauer B, Breloeer M, Salchow F, Staak C (1998) Host preferences of tsetse (Diptera: Glossinidae) based on bloodmeal identifications. Med Vet Entomol 12: 169-180. 
Cumming GS (2004) On the relevance of abundance and spatial pattern for interpretations of host-parasite association data. Bull Entomol Res 94: 401-409.

El Shoura SM (1990) Nuttalliella namaqua (Acarina: Ixodoidea: Nuttalliellidae) redescription of the female morphology in relation to the families Argasidae and Ixodidae. Acarologia 31: 349-355.

El Shoura SM, Hoogstraal H, Roshdy MA (1984) Nuttalliella namaqua (Ixodoidea: Nuttalliellidae): female internal morphology. J Parasitol 70: 114-120.

Estrada-Peña A, Mangold AJ, Nava S, Venzal JM, Labruna M, Guglielmone AA (2010) A review of the systematics of the tick family Argasidae (Ixodida). Acarologia 50: 317-333.

FitzSimons V (1938) Transvaal Museum expedition to South-West Africa and Little Namaqualand, May to August 1937. Reptiles and Amphibians. Ann Transvaal Mus 19: 153-209.

Guglielmone AA, Robbins RG, Apanaskevich DA, Petney TN, Estrada-Pena A, Horak IG, Shao R, Barker SC (2010) The Argasidae, Ixodidae and Nuttalliellidae (Acari: Ixodida) of the world: a list of valid species names. Zootaxa 2528: 1-28.

Hoogstraal H (1985) Argasid and Nuttalliellid ticks as parasites and vectors. Adv Parasitol 24: 135-238.

Horak IG, Lutermann H, Medger K, Apanaskevich DA, Matthee CA (2012) Natural hosts of the larvae of Nuttalliella sp. (N. namaqua?) (Acari: Nuttalliellidae). Onderstepoort J Vet Res 79: 405.

Keirans JE, Clifford CM, Hoogstraal H, Easton ER (1976) Discovery of Nuttalliella namaqua Bedford (Acarina: Ixodoidea: Nuttalliellidae) in Tanzania and redescription of the female based on scanning electron microscopy. Ann Entomol Soc Amer 69: 926-932.

Kent RJ, Norris DE (2005) Identification of mammalian blood meals in mosquitoes by a multiplexed polymerase chain reaction targeting cytochrome B. Am J Trop Med Hyg 73: 336-342.

Klompen JS, Black WC 4th, Keirans JE, Oliver JH Jr. (1996) Evolution of ticks. Annu Rev Entomol 41: 141161.

Kocher TD, Thomas WK, Meyer A, Edwards SV, Pääbo S, Villablanca FX, Wilson AC (1989) Dynamics of mitochondrial DNA evolution in animals: amplification and sequencing with conserved primers. Proc Natl Acad Sci USA 86: 6196-61200. 
Koh LP, Dunn RR, Sodhi NS, Colwell RK, Proctor HC, Smith VS (2004) Species coextinctions and the biodiversity crisis. Science 305: 1632-1634.

Krasnov BR, Khokhlova IS, Shenbrot GI, Poulin R (2008) How are the host spectra of hematophagous parasites shaped over evolutionary time? Random choice vs selection of a phylogenetic lineage. Parasitol Res 102: 1157-1164.

Krasnov BR, Mouillot D, Shenbrot GI, Khokhlova IS, Poulin R (2010) Deconstructing spatial patterns in species composition of ectoparasite communities: The relative contribution of host composition, environmental variables and geography. Global Ecol Biogeograph 19: 515-526.

Laskay ÜA, Burg J, Kaleta EJ, Vilcins IM, Telford Iii SR, Barbour AG, Wysocki VH (2012) Development of a host blood meal database: de novo sequencing of hemoglobin from nine small mammals using mass spectrometry. Biol Chem 393: 195-201.

Latif AA, Putterill JF, de Klerk DG, Pienaar R, Mans BJ (2012) Nuttalliella namaqua (Ixodoidea: Nuttalliellidae): first description of the male, immature stages and re-description of the female. PLoS One 7: e41651.

Mans BJ, de Klerk D, Pienaar R, Latif AA (2011) Nuttalliella namaqua: a living fossil and closest relative to the ancestral tick lineage: implications for the evolution of blood-feeding in ticks. PLoS One 6:e23675.

Mans BJ, de Klerk D, Pienaar R, de Castro MH, Latif AA. (2012) The mitochondrial genomes of Nuttalliella namaqua (Ixodoidea: Nuttalliellidae) and Argas africolumbae (Ixodoidae: Argasidae): estimation of divergence dates for the major tick lineages and reconstruction of ancestral blood-feeding characters. PLoS One 7: e49461.

Mihalca AD, Gherman CM, Cozma V (2011) Coendangered hard-ticks: threatened or threatening? Parasit Vectors 4:71.

Nava S, Gulgielmone AA (2013) A meta-analysis of host specificity in Neotropical hard ticks (Acari: Ixodidae). Bull Entomol Res 103: 216-224.

Ngo KA, Kramer LD (2003) Identification of mosquito bloodmeals using polymerase chain reaction (PCR) with order-specific primers. J Med Entomol 40: 215-222. 
Oshaghi MA, Chavshin AR, Vatandoost H (2006) Analysis of mosquito bloodmeals using RFLP markers. Exp Parasitol 114: 259-264.

Roberts A (1937) The Barlow Expedition to South-West Africa and Little Namaqualand. Archive Reports. Ditsong National Museum of Natural History, South Africa.

Scott MC, Harmin JR, Tsao JI, Jones CJ, Hickling GJ (2012) Reverse line blot probe design and polymerase chain reaction optimization for bloodmeal analysis of ticks from the eastern United States. J Med Entomol 49: 697-709.

Stanley EL, Bauer AM, Jackman TR, Branch WR, Mouton PLeFN (2011) Between a rock and a hard polytomy: Rapid radiation in the rupicolous girdled lizards (Squamata: Cordylidae). Mol Phylogenet Evol 58: 5370.

Wells K, O’Hara RB, Pfeiffer M, Lakim MB, Petney TN, Durden LA (2012) Inferring host specificity and network formation through agent-based models: tick-mammal interactions in Borneo. Oecologia 172: 307-316.

Whiting AS, Bauer AM, Sites JW, Jr. (2003) Phylogenetic relationships and limb loss in sub-Saharan African scincine lizards (Squamata: Scincidae). Mol Phylogenet Evol 29: 582-598.

Wickramasekara S, Bunikis J, Wysocki V, Barbour AG (2008) Identification of residual blood proteins in ticks by mass spectrometry proteomics. Emerg Infect Dis 14: 1273-1275. 
Table 1 Gut meal analysis of field collected N. namaqua. Indicated are the locality and the habitat from which ticks were collected, the presence of nucleated red blood cells in the gut, the best BLASTN hit and the number of clones sequenced in parenthesis, as well as the percentage identity to the best BLASTN hit. The Genbank accession numbers for the different clones are also indicated. Sequences from Nn1 were reported in a previous study (Mans et al. 2011). *These sequences considered to be closely related species to the best BLAST hit.

\begin{tabular}{|c|c|c|c|c|c|c|}
\hline Sample & $\begin{array}{l}\text { Locality/ } \\
\text { Gender }\end{array}$ & Habitat & $\begin{array}{l}\text { Nucleated } \\
\text { RBC }\end{array}$ & $\begin{array}{l}\text { Best BLASTN hit } \\
\text { (number of clones) }\end{array}$ & $\begin{array}{l}\text { Identity } \\
(\%)\end{array}$ & GI number \\
\hline \multirow[t]{4}{*}{ Nn1 } & Voëlklip / & In ground & Yes & Karusasaurus polyzonus (12) & 99 & 334562344 \\
\hline & Female & crevice & & Cordylus ukingensis (5) & $88^{*}$ & 334562343 \\
\hline & & & & Cordylus cordylus (6) & $94 *$ & 308096005 \\
\hline & & & & Ninurta coeruleopunctatus (3) & $88^{*}$ & 334562345 \\
\hline \multirow[t]{2}{*}{ Nn2 } & Krymekaar/ & Underside & Yes & Pachydactylus weberi (10) & $87 *$ & JQ739170 \\
\hline & Female & $\begin{array}{l}\text { of rock } \\
\text { overhang }\end{array}$ & & Procavia capensis (2) & 97 & КС907408 \\
\hline Nn3 & $\begin{array}{l}\text { Krymekaar/ } \\
\text { Female }\end{array}$ & $\begin{array}{l}\text { Underside } \\
\text { of rock } \\
\text { overhang }\end{array}$ & Yes & Pachydactylus weberi (10) & $87^{*}$ & JQ739170 \\
\hline Nn4 & $\begin{array}{l}\text { Krymekaar/ } \\
\text { Female }\end{array}$ & Hyrax den & Yes & Pachydactylus bibronii (10) & 99 & JQ739169 \\
\hline Nn5 & $\begin{array}{l}\text { Voëlklip/ } \\
\text { Female }\end{array}$ & $\begin{array}{l}\text { In ground } \\
\text { crevice }\end{array}$ & Yes & Pachydactylus bibroni (10) & 99 & JQ739169 \\
\hline Nn6 & $\begin{array}{l}\text { Krymekaar/ } \\
\text { Female }\end{array}$ & Under flint & Yes & Mabuya sulcata (10) & 98 & JQ739172 \\
\hline \multirow[t]{3}{*}{ Nn7 } & Voëlklip/ & In ground & Yes & Pachydactylus bibronii (4) & 99 & JQ739169 \\
\hline & Female & crevice & & Pachydactylus namaquensis (3) & $95^{*}$ & JQ739171 \\
\hline & & & & Pachydactylus weberi (1) & $87^{*}$ & JQ739170 \\
\hline Nn8 & $\begin{array}{l}\text { Krymekaar/ } \\
\text { Female }\end{array}$ & Under flint & Yes & Pachydactylus bibronii (10) & 99 & JQ739169 \\
\hline Nn9 & $\begin{array}{l}\text { Krymekaar/ } \\
\text { Female }\end{array}$ & $\begin{array}{l}\text { Underside } \\
\text { of rock } \\
\text { overhang }\end{array}$ & Yes & Pachydactylus weberi (10) & $87^{*}$ & JQ739170 \\
\hline
\end{tabular}


Table 2 Potential hosts described for $N$. namaqua. *In the case of blood-meal analysis the minimum number of animals that were parasitized is indicated, assuming that each tick fed independently. In the case of the birds, ticks were found in two independent nests.

\begin{tabular}{|c|c|c|c|c|c|}
\hline Animal & $\begin{array}{l}\text { Number } \\
\text { of ticks }\end{array}$ & $\begin{array}{l}\text { Life } \\
\text { stage }\end{array}$ & $\begin{array}{l}\text { Number } \\
\text { of } \\
\text { animals }\end{array}$ & $\begin{array}{l}\text { Collection } \\
\text { method }\end{array}$ & Reference \\
\hline \multicolumn{6}{|l|}{ Mammals } \\
\hline Suricata suricatta hahni & 10 & Adult & 2 & On host & Roberts, 1937 \\
\hline Parotomys brantsi brantsi & 1 & Adult & 1 & On host & Roberts, 1937 \\
\hline Aethomys chrysophilus & 58 & Larvae & 6 & On host & Horak et al. 2012 \\
\hline Acomys spinosissimus & 9 & Larvae & 3 & On host & Horak et al. 2012 \\
\hline Micaelamys namaquensis & 154 & Larvae & 10 & On host & Horak et al. 2012 \\
\hline Procavia capensis & 1 & Adult & $1 *$ & Blood-meal & This study \\
\hline \multicolumn{6}{|l|}{ Reptiles } \\
\hline Karusasaurus polyzonus & 1 & Adult & $1 *$ & Blood-meal & Mans et al. 2011 \\
\hline Cordylus cf. ukingensis & 1 & Adult & $1 *$ & Blood-meal & Mans et al. 2011 \\
\hline Cordylus cf. cordylus & 1 & Adult & $1 *$ & Blood-meal & Mans et al. 2011 \\
\hline Ninurta cf. coeruleopunctatus & 1 & Adult & $1 *$ & Blood-meal & Mans et al. 2011 \\
\hline Pachydactylus cf. weberi & 3 & Adult & $3 *$ & Blood-meal & This study \\
\hline Pachydactylus bibronii & 4 & Adult & $4^{*}$ & Blood-meal & This study \\
\hline Pachydactylus cf. namaquensis & 1 & Adult & $1 *$ & Blood-meal & This study \\
\hline Mabuya sulcata & 1 & Adult & $1 *$ & Blood-meal & This study \\
\hline \multicolumn{6}{|l|}{ Birds } \\
\hline Hirundo abyssinica unitatis & 2 & Adult & $2 *$ & Nest & Keirans et al. 1976 \\
\hline
\end{tabular}

